\title{
Memory Reconsolidation Engages Only a Subset of Immediate-Early Genes Induced during Consolidation
}

\author{
Laura S. J. von Hertzen and K. Peter Giese \\ Wolfson Institute for Biomedical Research, University College London, London WC1E 6BT, United Kingdom
}

\begin{abstract}
The relationship between memory consolidation and reconsolidation at the molecular level is poorly understood. Here, we identify three immediate-early genes that are differentially regulated in the mouse hippocampus after contextual fear conditioning and reactivation of the context-shock memory: serum- and glucocorticoid-induced kinase 1 (SGK1), SGK3, and nerve growth factor-inducible gene B (NGFI-B). The upregulation of SGK1 expression was not specific for the context-shock association and therefore not suitable for a comparison of contextual memory consolidation and reconsolidation. SGK3 expression was upregulated during both consolidation and reconsolidation. Analysis of SGK3 expression showed that expression changes elicited by a context-shock association during consolidation can subsequently be recapitulated during reconsolidation and that the transcriptional changes induced by retrieval depend on the remoteness of the memory. On the other hand, we found that NGFI-B is regulated during consolidation but not reconsolidation. This consolidation-specific regulation occurs in hippocampal area CA1. Our discovery of a consolidation-specific transcription indicates that reconsolidation is only a partial recapitulation of consolidation at the transcriptional level. Such partial rather than total recapitulation may have evolved as a more economic and reliable mechanism for organisms to modify memory.
\end{abstract}

Key words: gene expression; nurr77; N10; contextual fear conditioning; hippocampus; memory

\section{Introduction}

A newly formed memory, initially sensitive to interfering agents, is stabilized for long-term storage through a process generally referred to as memory consolidation. During memory consolidation, de novo transcription and protein synthesis occur, and inhibition of either of these processes specifically blocks long-term but not short-term memory (for review, see Silva and Giese, 1994; Dudai, 2004). It was long considered that a memory undergoes consolidation only once and that subsequently it would be permanent and unmodifiable. However, this consolidation theory has been challenged by the finding that reactivation of consolidated memory can return it to a labile state (Nader et al., 2000; Sara, 2000). Such memory reactivation also induces de novo transcription (Hall et al., 2001; Strekalova et al., 2003) and inhibition of transcription or protein synthesis within a short time window after the recall impairs the previously consolidated memory (Nader et al., 2000; Taubenfeld et al., 2001; Anokhin et al., 2002; Debiec et al., 2002; Kida et al., 2002; Milekic and Alberini, 2002). Thus, memory reactivation induces a second consolidation process, which has been named reconsolidation (Nader et al., 2000; Sara, 2000).

Only a few studies have tried to compare molecular processes

Received Feb. 27, 2004; revised Dec. 19, 2004; accepted Jan. 7, 2005.

This work was supported by the Wellcome Trust (061962). L.S.J.v.H. is in the 4 year PhD in Neuroscience Programme at the University College London. We thank Drs. Elaine Irvine, Sheena Josselyn, Satoshi Kida, Jonathan Lee, Maria Milekic, Keiko Mizuno, Marco Peters, Boris Rogelj, Steven Rose, Jeff Vernon, and Chris Yeo for technical help and/or critical comments on previous versions of this manuscript.

Correspondence should be addressed to Dr. Karl Peter Giese, Wolfson Institute for Biomedical Research, University College London, Gower Street, London WC1E 6BT, UK. E-mail: p.giese@ucl.ac.uk.

D01:10.1523/JNEUROSCI.4707-04.2005

Copyright $\odot 2005$ Society for Neuroscience $\quad$ 0270-6474/05/251935-08\$15.00/0 occurring during memory consolidation and reconsolidation. An early study implied that consolidation and reconsolidation differ, because in the hippocampus, the transcription factor $\mathrm{C} / \mathrm{EBP} \beta$ is required for consolidation but not reconsolidation in a passive avoidance task (Taubenfeld et al., 2001). However, protein synthesis in the hippocampus is not required for reconsolidation in this task. Because consolidation and reconsolidation may engage different anatomical structures (Tronel and Sara, 2002; Bahar et al., 2004), this study is not suitable for a molecular comparison of consolidation and reconsolidation. More recently, antisense experiments revealed a double dissociation between consolidation and reconsolidation, indicating that the two processes differ (Lee et al., 2004). However, it is still unclear whether consolidation and reconsolidation engage completely different molecular processes or whether particular processes are shared. Studies have shown that the immediate-early genes (IEGs) c-fos and zif268 are upregulated in the hippocampus after contextual fear conditioning and memory reactivation (Stanciu et al., 2001; Hall et al., 2000, 2001; Strekalova et al., 2003). However, these upregulations are not specific for the context-shock association. Thus, these genes are not markers of memory consolidation and are unsuitable for comparing the molecular processes underlying consolidation and reconsolidation. To perform adequate comparisons, only association-specific transcriptions should be considered.

Here, we advance the molecular analysis of contextual fear memory consolidation and reconsolidation by analyzing transcriptional events in the mouse hippocampus. We found two context-shock-specific IEGs: serum- and glucocorticoidinduced kinase 3 (SGK3) (Kobayashi et al., 1999) and the nerve growth factor-inducible gene B (NGFI-B) (Milbrandt, 1988). Using these genes as markers, we show that (1) transcriptions spe- 
cific to the context-shock association can be recapitulated during reconsolidation, (2) contextual fear memory reconsolidation in the hippocampus depends on the remoteness of the memory, and (3) there are consolidation-specific transcriptions that do not recur during reconsolidation.

\section{Materials and Methods}

Animals. The subjects were housed in groups of two to four and maintained on a $12 \mathrm{~h}$ light/dark cycle with food and water ad libitum. All experiments were undertaken in accordance with the United Kingdom Animals (Scientific Procedures) Act, 1986. Two- to 5-month-old C57BL/ 6J $\times 129$ S2/SvHsd F1-hybrid male mice (Harlan, Bicester, UK) were used for the anisomycin study and all expression studies. Initially, 2- to 3-month-old C57BL/6J male mice (Charles River, London, UK) were used for setting up the latent inhibition (LI) protocol and assessing the freezing. For the LI expression studies, C57BL/6J × 129S2/SvHsd F1hybrid male mice were used as described above.

Contextual fear conditioning. We used background contextual fear conditioning (contextual fear conditioning with a tone presentation). Background contextual conditioning involves the hippocampus more strongly than conditioning without a tone presentation (foreground conditioning) (Phillips and LeDoux, 1994). Each mouse was placed into the conditioning chamber (Campden Instruments, Loughborough, UK) in a soundproof box. After a $120 \mathrm{~s}$ introductory period, a tone $(80 \mathrm{~dB}, 2.8$ $\mathrm{kHz}$ ) was presented for $30 \mathrm{~s}$, which coterminated with a $2 \mathrm{~s}$ foot shock $(0.75 \mathrm{~mA})$. After an additional $30 \mathrm{~s}$, the mouse was returned to its home cage. For contextual reexposure, the mice were returned to the conditioning chamber for $5 \mathrm{~min}$.

The mice were divided into five groups ( $n=6$ for each): (1) naïve; (2) $\mathrm{T}+1$, early memory consolidation group, killed $1 \mathrm{~h}$ after training; (3) $\mathrm{T}+25$, late memory consolidation group, killed $25 \mathrm{~h}$ after training; (4) $\mathrm{R}+1$, memory reactivation group, reexposed to the training context $24 \mathrm{~h}$ after training and killed $1 \mathrm{~h}$ after reexposure; and (5) $\mathrm{R}+1_{28 \text { days }}$, remote memory reactivation group, reexposed to the training context $28 \mathrm{~d}$ after training and killed $1 \mathrm{~h}$ after reexposure. Five control groups were included: (1) box group $(n=5)$, exposed to the training context for 3 min in the absence of foot shock and tone, returned to their home cage, and killed $1 \mathrm{~h}$ after exposure; (2) box-reexposed group (BoxR+1) $(n=6)$, exposed twice to the training context in the absence of both foot shock and tone with an interexposure interval of $24 \mathrm{~h}$ and killed $1 \mathrm{~h}$ after the second exposure; (3) tone group $(n=6)$, exposed to the training context for $3 \mathrm{~min}$ in the presence of the tone but in the absence of the foot shock; (4) LI group $(n=5)$, housed in the training context overnight, with water and food ad libitum, foot shocked $(0.75 \mathrm{~mA})$ for $2 \mathrm{~s}$ after $16 \mathrm{~h}$, and killed $1 \mathrm{~h}$ after the foot shock; and (5) BoxR $+1_{28 \text { days }}(n=5)$, exposed twice to the training context in the absence of foot shock and tone with an interexposure interval of $28 \mathrm{~d}$ and killed $1 \mathrm{~h}$ after the second exposure.

The behavior of the mice in the conditioning chamber was videotaped, and for $5 \mathrm{~min}$, freezing was assessed every $5 \mathrm{~s}$ for $2 \mathrm{~s}$; freezing was scored if no movements other than respiratory movements were detected. For statistical analysis, one-way ANOVA was used.

Anisomycin administration. Anisomycin was administered systemically immediately after memory reactivation induced $24 \mathrm{~h}$ after training. Anisomycin (Sigma, St. Louis, MO) was dissolved in $0.9 \%$ saline ( $\mathrm{pH}$ subsequently adjusted to 7.0-7.4), and mice were given injections of either 150 or $225 \mathrm{mg}$ of anisomycin per kilogram of body weight or an equivalent volume of $0.9 \%$ saline.

Quantitative real-time PCR. Hippocampi were fresh-frozen on dry ice and stored at $-80^{\circ} \mathrm{C}$. Total RNA was extracted using Trizol (Invitrogen, San Diego, CA) and purified through RNAeasy mini-columns (Qiagen, Hilden, Germany). RNA $(4 \mu \mathrm{g})$ from each sample was reverse transcribed using superscript II reverse transcriptase (Invitrogen). The obtained cDNA was diluted $1: 10$ and stored at $-20^{\circ} \mathrm{C}$. The cDNA samples were checked for genomic DNA contamination using a PCR that distinguishes between genomic DNA and cDNA for the hypoxanthine phosphoribosyltransferase (HPRT) gene. The primers used were HPRT forward 5'-GCTGGTGAAAAGGACCTCT-3' and HPRT-reverse $5^{\prime}$ CACAGGACTAGAACACCTGC- $3^{\prime}$, and the amplification conditions were $93^{\circ} \mathrm{C}$ for $2 \mathrm{~min}, 35$ times $\left(93^{\circ} \mathrm{C}\right.$ for $30 \mathrm{~s}, 58^{\circ} \mathrm{C}$ for $45 \mathrm{~s}, 72^{\circ} \mathrm{C}$ for 1 $\min$ ), and $72^{\circ} \mathrm{C}$ for $10 \mathrm{~min}$. Real-time PCR primers for SGK-1, NGFI-B, SGK3, and HPRT (control) were designed with Primer Express 2.0 software (Applied Biosystems, Foster City, CA): NGFI-B Forward, 5'-TGGCTTTGGTGATTGGATTGA-3'; NGFI-B Reverse 5'-GGAGCCCGTGTCGATCAGT-3'; SGK-1 Forward 5' ${ }^{\prime}$-TTCTGAACAAGCCTCTCCAGTTG-3'; SGK-1 $1_{\text {Reverse }}$ 5'-GGCACCCAGCCTCTTGGT-3'; SGK3 Forward, 5'-TTCACTGAAGAAACGGTTCCCTAT-3'; SGK3 ${ }_{\text {Reverse }}$, 5' -AAAAACCAACAAATGCATCATCTG-3'; HPRT Forward, 5' -ATACAGGCCAGACTTTGTTGGATT-3'; HPRT Reverse, 5' $^{\prime}$-TCACTAATGACACAAACGTGATTCAA-3'.

Quantitative real-time PCR (qPCR) was performed on the ABI7000 PCR system (Applied Biosystems) using SYBR Green as a fluorescent marker. For each sample, triplicates of $25 \mu \mathrm{l}$ reactions were prepared using $2 \times$ SYBR Green PCR Master Mix (Applied Biosystems) along with $1 \mu \mathrm{l}$ of $\mathrm{cDNA}$ and the appropriate final primer concentration, which was determined empirically (NGFI-B Forward $=900 \mathrm{nM}$; NGFI- Reverse $_{\text {Re }}=300$ $\mathrm{nM}$; SGK-1 $1_{\text {Forward }}=900 \mathrm{nM}$; SGK-1 $1_{\text {Reverse }}=300 \mathrm{nM}$; SGK3 $3_{\text {Forward }}=$ $300 \mathrm{~nm} ; \mathrm{SGK}_{\text {Reverse }}=300 \mathrm{~nm} ; \mathrm{HPRT}_{\text {Forward }}=900 \mathrm{~nm} ; \mathrm{HPRT}_{\text {Reverse }}=$ $900 \mathrm{~nm})$. The reaction was performed on MicroAmp Optical 96-well reaction plates (Applied Biosystems) capped with an ABI Prism Optical Adhesive Cover (Applied Biosystems). The PCR product levels were measured continuously by ABI7000 during 40 cycles. The cycle conditions were $50^{\circ} \mathrm{C}$ for $2 \mathrm{~min}$, followed by 40 times $\left(95^{\circ} \mathrm{C}\right.$ for $15 \mathrm{~s}, 60^{\circ} \mathrm{C}$ for 1 min). The specificity of the PCR reactions was confirmed by DNA sequencing. The primer concentrations were optimized so that the amplification efficiencies of both the template and the endogenous HPRT were identical throughout a range of mRNA dilutions. For each sample, the mean threshold cycle (CT) was determined. The comparative CT method was used in which the target mRNA amount was normalized to the endogenous HPRT mRNA amount and calibrated to the mRNA amount in the naive group. For statistical analysis, one-way ANOVA or one-way ANOVA on ranks and Student-Newman-Keuls or Dunn's post hoc tests were used.

In situ hybridization. Immediately after dissection, the brains were frozen in isopentane cooled to -20 to $-30^{\circ} \mathrm{C}$, then transferred to dry ice. Fifteen-micrometer coronal brain sections were cut on a cryostat and thaw-mounted onto superfrost slides (Invitrogen). The sections were fixed in $4 \%$ paraformaldehyde/PBS for 5 min on ice, rinsed with PBS for $1 \mathrm{~min}$, dehydrated in $70 \%$ ethanol for $5 \mathrm{~min}$, and stored at $4^{\circ} \mathrm{C}$ in $95 \%$ ethanol. A 45-mer oligonucleotide complementary to the NGFI-B mRNA, 5'-ATTGGTAGGGGAGGCATCTGGAGGCTGCTTGGGTTTTGAAGGTAG-3', was synthesized by Invitrogen (Paisley, UK) and end-labeled with $\left[\alpha^{-}{ }^{35} \mathrm{~S}\right]$ dATP $(1000 \mathrm{Ci} / \mathrm{mmol}$; Amersham Biosciences, Bucks, UK) using terminal deoxynucleotidyl transferase (Promega, Madison, WI). Air-dried slides were hybridized at $42^{\circ} \mathrm{C}$ for $16 \mathrm{~h}$ in a humidifying chamber with $50 \mu$ l of hybridization buffer $[50 \%(\mathrm{v} / \mathrm{v})$ formamide, $4 \times$ SSC, pH 7.0, $25 \mathrm{~mm}$ sodium phosphate, $\mathrm{pH} 7.0,1 \mathrm{~mm}$ sodium pyrophosphate, $20 \mathrm{~mm}$ DTT, $2 \times$ Denhardt's solution, $200 \mu \mathrm{g} / \mathrm{ml}$ heat-denatured salmon sperm DNA, $10 \%(\mathrm{w} / \mathrm{v})$ dextran sulfate, and $100,000-300,000 \mathrm{cpm}^{35} \mathrm{~S}$-labeled probe] per slide. Sections were washed twice in $1 \times \mathrm{SSC}$ at $55^{\circ} \mathrm{C}$ for $30 \mathrm{~min}$, transferred through $0.1 \times \mathrm{SSC}, 70 \%$ ethanol, and 95\% ethanol, and air dried. To control for nonspecific hybridization, adjacent sections were incubated with radiolabeled oligonucleotide in the presence of an excess concentration (100X) of unlabeled oligonucleotide probe. The sections were exposed to a ${ }^{35} \mathrm{~S}$-sensitive film for autoradiography together with ${ }^{14} \mathrm{C}$ microscale standards (Amersham Biosciences) for 2 weeks at room temperature. The autoradiograph of every brain section was imaged with a monochrome camera. The resultant images were calibrated (nanoCuries per gram) with reference to the ${ }^{14} \mathrm{C}$ standards [nanoCuries per gram of tissue equivalent (TE)], and the intensity of the signal was quantified/analyzed using the MCID M5+ image analysis system (Imaging Research, St. Catherines, Ontario, Canada). The intensity of the signal was measured as the number of counts ( 1 count $=1$ pixel $)$ above a threshold density $(29.63 \mathrm{nCi} / \mathrm{g} \mathrm{TE})$ at which the signal was detected in the control samples. The size of the CA1 areas analyzed between naive and trained mice was not significantly different (one-way ANOVA; $F_{(1,46)}=0.12 ; p=0.73$ ) (data not shown). 


\section{Results}

Experimental groups to compare contextual memory consolidation and reconsolidation

We investigated the hippocampal expression of three IEGs (SGK1 (Webster et al., 1993), SGK3, and NGFI-B), two of which we had

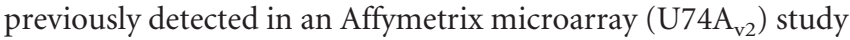
comparing hippocampal gene expression after contextual fear conditioning and reactivation of the context-shock memory (our unpublished observation). We studied the regulation of these genes during contextual fear memory consolidation and reconsolidation in mice, using a spectrum of conditioning and control groups (Fig. $1 A$ ). Our contextual fear conditioning protocol induced substantial freezing $24 \mathrm{~h}$ after training (51.8 $\pm 5.6 \%)$, whereas the context without conditioning did not evoke freezing $(0.5 \pm 0.4 \%)$; one-way ANOVA showed a significant difference between the two groups $\left(F_{(1,14)}=48.6 ; p<0.001\right)$ (Fig. $1 B$ ). Furthermore, our LI protocol significantly reduced contextual freezing $24 \mathrm{~h}$ after the foot shock $(4.2 \pm 1.7 \%)$ compared with freezing induced by the contextual fear-conditioning protocol $\left(31.4 \pm 7.7 \%\right.$; one-way ANOVA; $\left.F_{(1,10)}=12.3 ; p<0.01\right)$ (Fig. $1 C)$. Thus, mice in the LI group did not associate the context with the foot shock, allowing this group to be used as a control for gene expression induced by the foot shock alone.

\section{A $5 \mathrm{~min}$ reexposure to the training context triggers memory reconsolidation but not extinction}

To confirm that our reexposure protocol induced protein synthesis-dependent reconsolidation, anisomycin was administered systemically immediately after reexposure performed $24 \mathrm{~h}$ after training. Contextual freezing was assessed $48 \mathrm{~h}$ after training (Fig. 2A). Anisomycin significantly reduced contextual freezing $\left(\operatorname{ani}_{(150 \mathrm{mg} / \mathrm{kg})}\right.$ group $=25.7 \pm 5.9 \% ; \operatorname{ani}_{(225 \mathrm{mg} / \mathrm{kg})}$ group $=21.3 \pm$ $3.8 \%)$ compared with the saline group $(43.9 \pm 5.6 \%$; $p<0.05$ for both; one-way ANOVA; $F_{(2,26)}=5.1 ; p<0.05$ ) (Fig. 2 B). Thus, our $5 \mathrm{~min}$ reexposure protocol induced memory reconsolidation. Furthermore, freezing of the saline group on test 2 was not significanty different from that on test 1 (one-way ANOVA; $F_{(1,22)}=1.4 ; p=0.20$ ) (Fig. $2 C$ ), indicating that our protocol did not induce contextual fear memory extinction.

Because our $5 \mathrm{~min}$ retrieval test induced reconsolidation but not extinction, the changes in gene expression observed after retrieval are related to memory reconsolidation and not extinction. Furthermore, the changes observed are unlikely to be part of the retrieval process per se (retrieval occurs too quickly to depend on transcriptional changes), but rather a part of the retrievalinduced reconsolidation process.

\section{SGK1 mRNA expression in the hippocampus is regulated after contextual fear conditioning and reexposure to the context}

To compare the expression profiles of $S G K 1$ after contextual fear conditioning and reactivation of the context-shock memory, we first studied SGK1 mRNA expression using qPCR in four groups of mice (naive, $\mathrm{T}+1, \mathrm{~T}+25, \mathrm{R}+1$ ) (Fig. $3 A$ ). One-way ANOVA showed a significant difference in $S G K 1$ expression between the four groups $\left(F_{(3,20)}=9.02 ; p<0.001\right)$. Post hoc analysis showed that $S G K 1$ was significantly upregulated $1 \mathrm{~h}$ after contextual fear conditioning compared with naive mice $(p<0.01)$. Furthermore, $25 \mathrm{~h}$ after contextual fear conditioning, $S G K 1$ expression had returned to the baseline level ( $p=0.83$ for naive vs $\mathrm{T}+25$ and $p<0.01$ for $\mathrm{T}+1$ vs $\mathrm{T}+25)$. However, $25 \mathrm{~h}$ after conditioning, $S G K 1$ expression was upregulated when the memory had been reactivated $24 \mathrm{~h}$ after con-
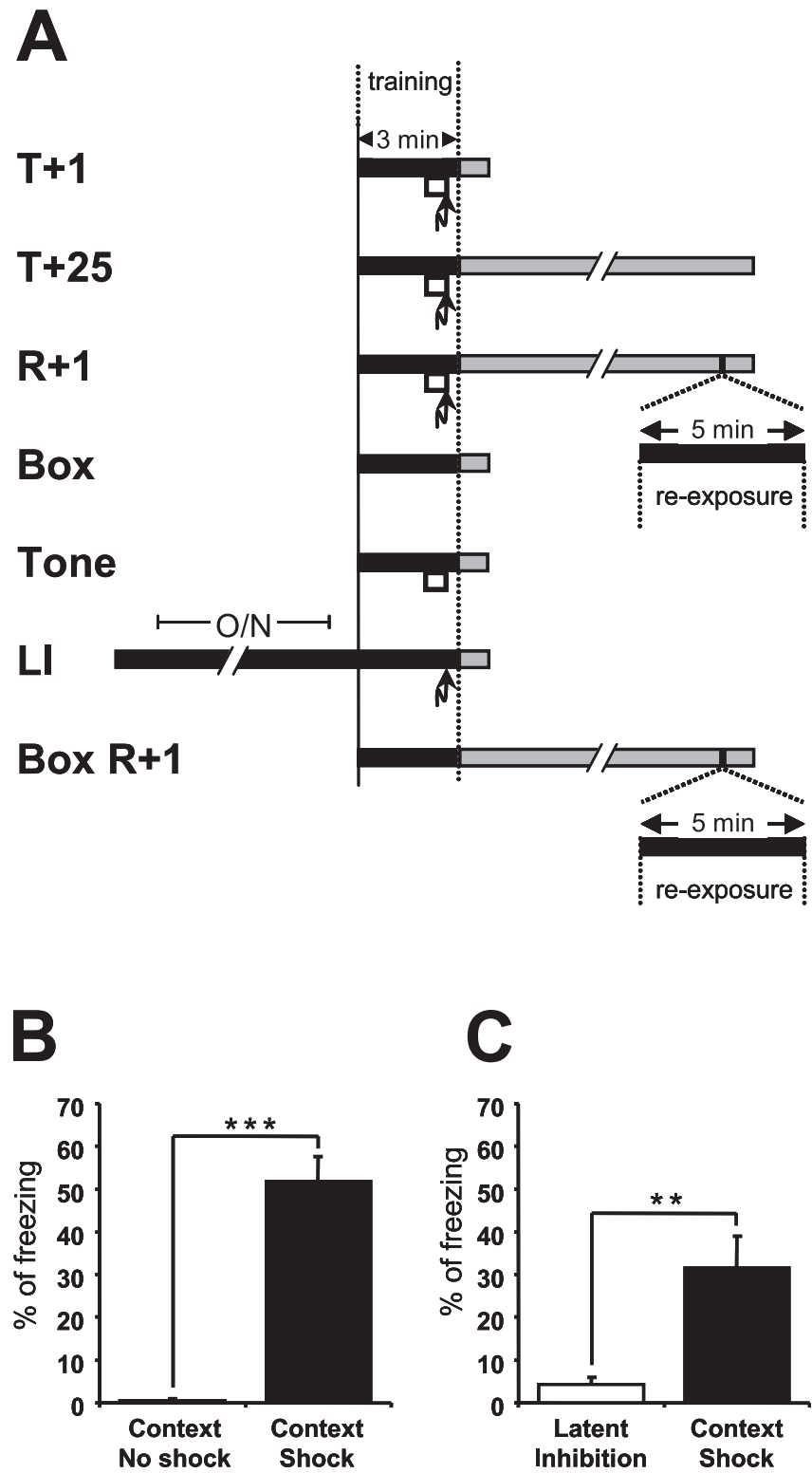

Figure 1. Experimental design and contextual freezing scores. $\boldsymbol{A}$, Experimental design to investigate changes in hippocampal mRNA expression induced by contextual fear conditioning. The black boxes indicate exposure to the training context, the white boxes represent a 30 s tone, the arrows indicate the foot shock, and the gray boxes show the time until the animals were killed. The following groups were studied: $\mathrm{T}+1$, trained and killed $1 \mathrm{~h}$ after training; $\mathrm{T}+25$, trained and killed $25 \mathrm{~h}$ after training; $\mathrm{R}+1$, trained, reexposed $24 \mathrm{~h}$ after training and killed $1 \mathrm{~h}$ after reexposure; Box, exposed to training context and killed $1 \mathrm{~h}$ after exposure; Tone, exposed to the training context with a 30 s tone and killed $1 \mathrm{~h}$ after exposure; LI, LI control, mice were housed overnight $(0 / \mathrm{N})$ in the training context, shocked in the morning, and killed $1 \mathrm{~h}$ after the shock; Box R+1, exposed twice to the training context (interval, $24 \mathrm{~h}$ ) and killed $1 \mathrm{~h}$ after the second exposure. $\boldsymbol{B}$, Two exposures to the context without conditioning did not evoke a freezing response $(B 0 x \mathrm{R}+1)$. The freezing score during a second exposure, $24 \mathrm{~h}$ after the first exposure, is shown. Contextual fear conditioning induced freezing to context $24 \mathrm{~h}$ after training $(\mathrm{R}+1)$ $\left(n_{\text {context no shock }}=6 ; n_{\text {context shock }}=10\right)$. Data are means \pm SEM; ${ }^{* * *} p<0.001$. C, Housing the mice $0 / \mathrm{N}$ in the training context, the LI protocol, significantly prevented an association between the foot shock and the context as indicated by reduced contextual freezing $24 \mathrm{~h}$ after the foot $\operatorname{shock}\left(n_{\text {latent inhibition }}=6 ; n_{\text {context shock }}=6\right)$. Data are means $\pm S E M ;{ }^{* *} p<0.01$.

ditioning $(p<0.01)$. This upregulation was of similar amplitude to that observed after conditioning.

We used the Box and LI groups to investigate whether the SGK1 expression change after conditioning was specific to the learned context-shock association or whether it was induced by 
A

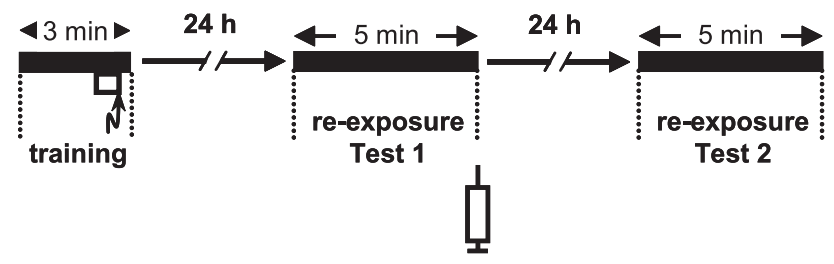

B
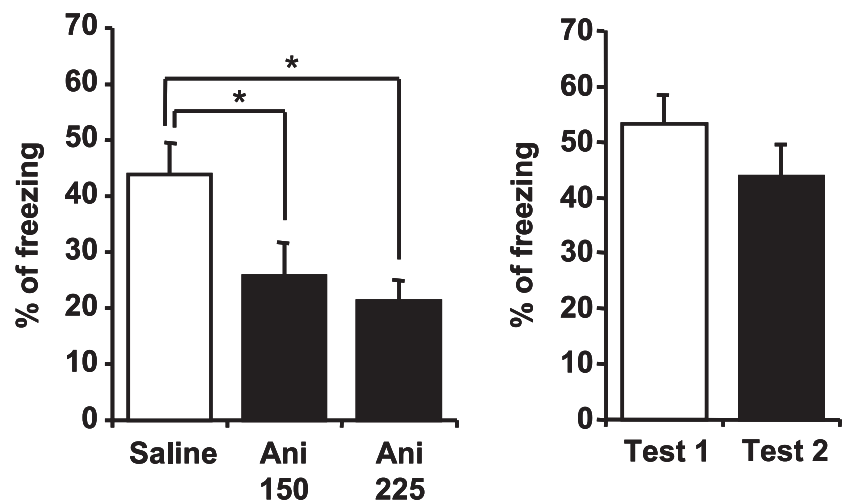

Figure 2. A 5 min reexposure to the training context triggers memory reconsolidation but not extinction. $\boldsymbol{A}$, Experimental procedure for anisomycin administration. The white box represents a 30 s tone, the arrow indicates the foot shock, and the syringe indicates the intraperitoneal injection of anisomycin. $\boldsymbol{B}$, Systemic anisomycin (Ani) administration immediately after a 5 min reexposure significantly reduced contextual freezing assessed $24 \mathrm{~h}$ after the reexposure $\left(n_{\text {saline }}=12 ; n_{\text {ani }(150 \mathrm{mg} / \mathrm{kg})}=9 ; n_{\text {ani }(250 \mathrm{mg} / \mathrm{kg})}=8\right)$. Data are means $\pm \mathrm{SEM} ;{ }^{*} p<0.05 . C$, Reexposure to the context did not induce contextual memory extinction in the saline group.
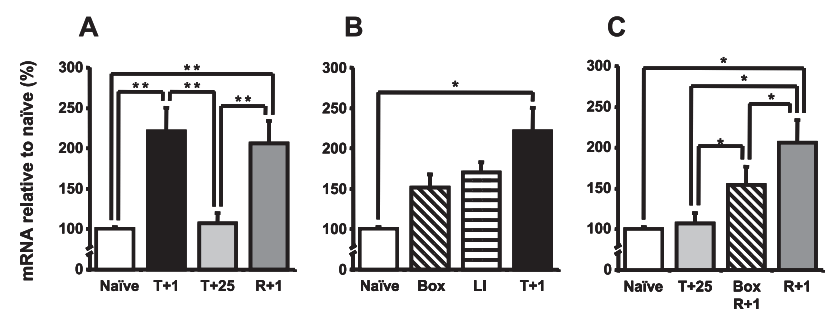

Figure 3. SGK1 mRNA expression in the hippocampus is upregulated after contextual fear conditioning and reexposure to the context. $A, q P C R$ showed that SGK1 mRNA expression was upregulated in the hippocampus $1 \mathrm{~h}$ after contextual fear conditioning and $1 \mathrm{~h}$ after contextshock memory reactivation compared with the naive and $T+25$ group. $B$, SGK1 mRNA expression in the hippocampus did not significantly differ in the Box, LI, and T+1 groups. Thus, the upregulation after conditioning was not specific for the learned association. (The naive and $\mathrm{T}+1$ groups are the same as in $\boldsymbol{A}$.) $\boldsymbol{C}$, SGK1 mRNA expression in the hippocampus significantly differed in the Box $R+1$ versus $R+1$ and in the $T+25$ versus Box $R+1$ groups. Thus, upregulation of SGK-1 expression after reexposure appeared to be induced in part by the context alone and in part by fear or by context-shock memory reactivation. Data are means $\pm \mathrm{SEM}$; ${ }^{*} p<$ $0.05 ;{ }^{* *} p<0.01$.

the foot shock alone or context alone (Fig. 3B). SGK1 expression in the naive, Box, $\mathrm{LI}$, and $\mathrm{T}+1$ groups was compared (one-way ANOVA on ranks; $\left.H_{(3,18)}=13.7 ; p<0.01\right)$. Post hoc analysis showed that $S G K 1$ expression in neither the Box nor the LI group was significantly different from $S G K 1$ expression in the $\mathrm{T}+1$ group ( $p>0.05$ for both), although there was a trend toward higher $S G K 1$ expression in the $\mathrm{T}+1$ group. Thus, the upregula- tion of SGK1 expression after contextual fear conditioning was not specific to context-shock association and could be induced, for example, by the novel environment or by fear.

Furthermore, we used the BoxR +1 group to study whether the upregulation of SGK1 expression after reexposure was induced by the context alone (Fig. 3C). SGK1 expression in the naive, $\mathrm{T}+25$, BoxR +1 , and $\mathrm{R}+1$ groups was compared (one-way ANOVA on ranks; $\left.H_{(3,20)}=15.4 ; p<0.01\right)$. Post hoc analysis revealed a significant difference between $S G K 1$ expression in the BoxR +1 and $\mathrm{R}+1$ groups $(p<0.05)$. Additionally, $S G K 1$ expression significantly differed between the $\mathrm{T}+25$ and BoxR +1 groups $(p<0.05)$. Thus, upregulation of $S G K 1$ expression after reexposure appeared to be induced in part by the context alone and in part by fear or by the context-shock memory reactivation.

\section{Memory reactivation can trigger the recapitulation of an association-specific transcription: SGK3}

We also investigated the hippocampal expression profile of $S G K 3$ after contextual fear conditioning and reactivation of contextual fear memory (Fig. 4). A one-way ANOVA comparing the naive, $\mathrm{T}+1, \mathrm{~T}+25$, and $\mathrm{R}+1$ groups showed a significant difference in $S G K 3$ expression between the four groups $\left(F_{(3,19)}=9.7 ; p<\right.$ 0.001 ) (Fig. 4A). Post hoc analysis revealed a significant upregulation of $S G K 3$ mRNA $1 \mathrm{~h}$ after conditioning compared with the expression in naive mice $(p<0.01)$. Furthermore, $25 \mathrm{~h}$ after conditioning, SGK3 expression had returned to baseline levels $(p=0.29$ for naive vs $\mathrm{T}+25$ and $p<0.05$ for $\mathrm{T}+1$ vs $\mathrm{T}+25)$. However, $25 \mathrm{~h}$ after conditioning, SGK3 expression was upregulated if the memory had been reactivated $24 \mathrm{~h}$ after conditioning $(p<0.001$ for $\mathrm{R}+1$ vs naive and $p<0.01$ for $\mathrm{R}+1$ vs $\mathrm{T}+25)$. This upregulation was of similar amplitude to that observed after conditioning ( $p=0.17$ for $\mathrm{T}+1 \mathrm{vs} \mathrm{R}+1)$.

To investigate whether the expression changes after contextual fear conditioning were specific to the learned context-shock association, we performed control experiments using the Box, LI, and Tone groups (Fig. $4 B, C$ ). SGK3 expression differed between the naive, Box, LI, and $\mathrm{T}+1$ groups (one-way ANOVA; $F_{(3,19)}=$ $14.5 ; p<0.001)$. Post hoc analysis showed that $S G K 3$ expression in the $\mathrm{T}+1$ group was significantly different from the Box $(p<$ $0.001)$ and the LI $(p<0.001)$ groups. The expression in the Box $(p=0.77)$ and LI $(p=0.60)$ groups was not significantly different from expression in the naive group. In addition, $S G K 3 \mathrm{ex}-$ pression significantly differed between the naive and Tone groups (one-way ANOVA; $F_{(1,10)}=0.68 ; p=0.43$ ). Thus, the upregulation of $S G K 3$ expression was specific to the contextshock association and therefore was part of the context-shock memory consolidation.

Furthermore, we used the BoxR +1 group to study whether repeated exposure to the context could have caused the upregulation of SGK3 expression (Fig. 4D). SGK3 expression in the naive, $\mathrm{T}+25$, BoxR +1 , and $\mathrm{R}+1$ groups was compared (one-way ANOVA; $\left.F_{(2,19)}=15.0 ; p<0.001\right)$. Post hoc analysis revealed a significant difference between $S G K 3$ expression in the BoxR +1 and $\mathrm{R}+1$ groups $(p<0.001)$. Additionally, the expression in the Box $\mathrm{R}+1$ group was not significantly different from expression in the naive $(p=0.47)$ or $\mathrm{T}+25(p=0.52)$ group. This finding, together with the observation that fear alone cannot cause an upregulation of $S G K 3$ expression (Fig. $4 B$ ), shows that upregulation of $S G K 3$ expression after reexposure was specific to contextshock memory reactivation. 
A

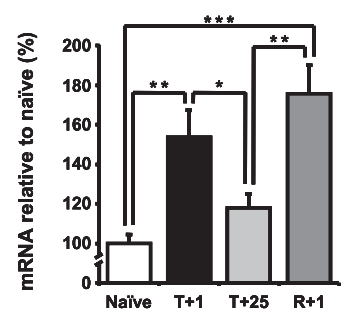

B

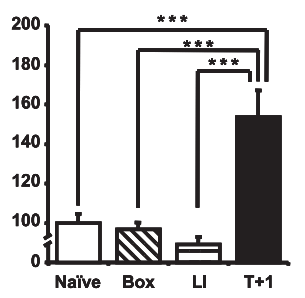

C

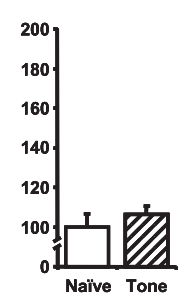

Figure 4. SGK3 mRNA expression in the hippocampus is upregulated during context-shock memory consolidation and reconsolidation. A, qPCR showed that SGK3 mRNA expression was upregulated in the hippocampus $1 \mathrm{~h}$ after contextual fear conditioning and $1 \mathrm{~h}$ after context-shock memory reactivation compared with the naive and $\mathrm{T}+25$ group. $\boldsymbol{B}, 5 G K 3 \mathrm{mRNA}$ expression in the hippocampus in the $\mathrm{T}+1$ group differed significantly from the expression in the Box and LI groups; the expression in both control groups did not differ significantly from that in the naive group. (The naive and $T+1$ groups are the same as in $A$.) C, SGK3 mRNA expression in the hippocampus did not significantly differ between the naive and Tone groups. Thus, the upregulation after conditioning was specific for the learned association. $D, S G K 3 \mathrm{mRNA}$ expression in the hippocampus in the $R+1$ group differed significantly from the expression in the $T+25$ and Box $R+1$ groups. Thus, upregulation after reexposure was specific for contextshock memory reactivation (naive, $T+25$, and $R+1$ are the same as in $A$ ). Data are means $\pm S E M ;{ }^{*} p<0.05 ;{ }^{* *} p<0.01$.

A

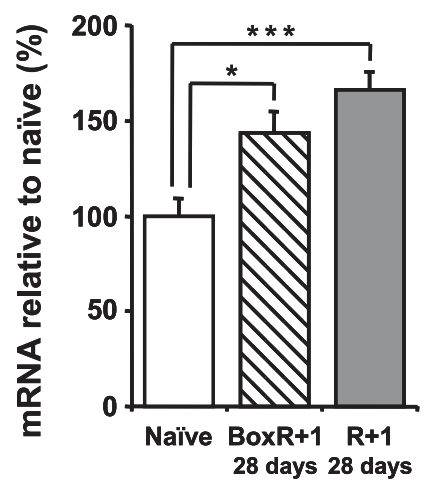

B

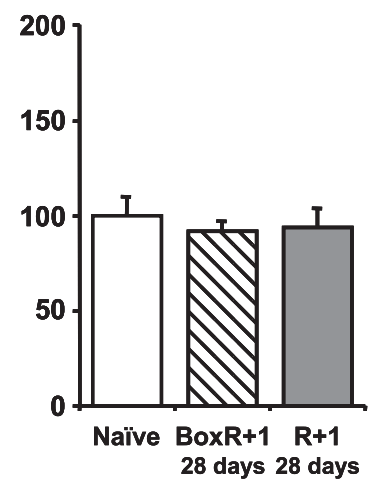

Figure 5. Reactivation of remote context-shock memory does not trigger an upregulation of SGK3 mRNA expression. $A$, SGK1 mRNA expression in the hippocampus in the naive group differed significantly from the expression in the Box $R+1_{28 \mathrm{~d}}$ and $R+1_{28 \mathrm{~d}}$ groups. However, SGK1 mRNA expression in the hippocampus in Box $R+1_{28 \mathrm{~d}}$ and $\mathrm{R}+1_{28 \mathrm{~d}}$ groups did not differ significantly. Data are means \pm SEM; ${ }^{*} p<0.05 ;{ }^{* * *} p<0.001$. $B$, SGK3 mRNA expression in the hippocampus was not significantly different in the naive, Box $R+1_{28 \mathrm{~d}}$ and $R+1_{28 \mathrm{~d}}$ groups

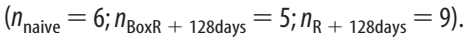

\section{Reactivation of remote contextual fear memory does not trigger an upregulation of $S G K 3$ expression in the hippocampus}

The hippocampus is known to play only a temporary role in the storage of contextual fear memory. Lesion studies have shown that the hippocampus is not needed for remote memory (Kim and Fanselow, 1992). We studied whether memory reactivation of a 28-d-old context-shock memory induces an upregulation of $S G K 1$ and $S G K 3$ expression in the hippocampus (Fig. 5). Animals in the $\mathrm{R}+1_{28 \text { days }}$ group showed robust freezing $28 \mathrm{~d}$ after conditioning $(50.2 \pm 7.0 \%)$. A one-way ANOVA between the naive, BoxR $+1_{28 \text { days }}$, and $\mathrm{R}+1_{28 \text { days }}$ groups showed a significant difference in $S G K 1$ expression between the three groups $\left(F_{(2,17)}=11\right.$.1; $p<0.001$ ) (Fig. 5A). Post hoc analysis revealed a significant upregulation of $S G K 1$ mRNA in the $\mathrm{R}+1_{28 \text { days }}$ group compared with the expression in naive mice $(p<0.001)$. However, there was also a significant upregulation of $S G K 1$ in the BoxR $+1_{28 \text { days }}$ group ( $p<0.05)$. This upregulation was not significantly different from that observed in the $\mathrm{R}+1_{28 \text { days }}$ group $(p=0.15)$, indicating that the upregulation triggered by a reexposure performed

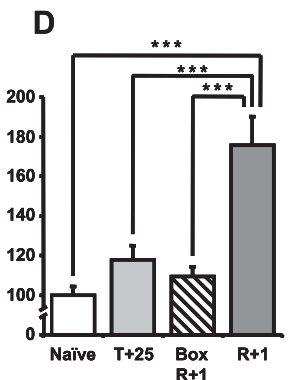

$28 \mathrm{~d}$ after training was induced by the context alone, and not by fear or by the reactivation of the context-shock memory. A one-way ANOVA between the naive, BoxR $+1_{28 \text { days, }}$, and $\mathrm{R}+1_{28 \text { days }}$ groups showed no significant difference in SGK3 expression between the three groups $\left(F_{(2,17)}=0.27 ; p=0.76\right)$ (Fig. $\left.5 B\right)$. Therefore, the upregulation of $S G K 3$, observed during reconsolidation of recent contextshock memory reactivation, is not triggered by remote context-shock memory reactivation.

\section{NGFI-B mRNA expression in the hippocampus is regulated during context-shock memory consolidation, but not during reconsolidation}

To compare the expression profiles of NGFI-B after contextual fear conditioning and reactivation of contextual fear memory, we first studied NGFI-B expression in four groups of mice (naive, $\mathrm{T}+1, \mathrm{~T}+25, \mathrm{R}+1$ ) (Fig. 6A). A one-way ANOVA between the naive, $\mathrm{T}+1, \mathrm{~T}+25$, and $\mathrm{R}+1$ groups showed a significant difference in NGFI-B expression between the four groups $\left(F_{(3,20)}=6.67 ; p<0.01\right)$. Post hoc analysis showed that NGFI-B is upregulated $1 \mathrm{~h}$ after contextual fear conditioning compared with the expression in naive mice $(p<0.01)$. Furthermore, $25 \mathrm{~h}$ after conditioning, NGFI-B expression had returned to baseline levels $(p=0.92)$. Comparison of the NGFI-B expression in the $\mathrm{R}+1$ versus $\mathrm{T}+25$ group $(p=0.21)$ and in the $R+1$ versus naive group ( $p=0.36$ ) revealed no significant upregulation in expression, indicating no regulation during reconsolidation.

To investigate whether the expression changes during contextual memory consolidation were specific to the learned contextshock association, we performed control experiments using the Box, LI, and Tone groups (Fig. 6B,C). NGFI-B expression differed between the naive, Box, LI, and $\mathrm{T}+1$ groups (one-way ANOVA; $\left.F_{(3,18)}=8.22 ; p<0.01\right)$. Post hoc analysis showed that $N G F I-B$ expression in the $\mathrm{T}+1$ group was significantly different from the Box $(p<0.01)$ and LI $(p<0.05)$ groups. The expression in the Box $(p=0.26)$ and LI $(p=0.24)$ groups was not significantly different from expression in the naive group. In addition, NGFI-B expression did not differ between the naive and Tone groups (one-way ANOVA; $F_{(1,10)}=0.2 ; p=0.7$ ). Thus, the upregulation of NGFI-B was specific to the context-shock association and therefore part of the context-shock memory consolidation.

\section{Upregulation of NGFI-B mRNA expression in the} hippocampus during context-shock memory consolidation occurred predominantly in area CA1

To localize the upregulation of NGFI-B mRNA expression in the hippocampus during contextual memory consolidation, we performed in situ hybridizations on coronal brain sections from naive and $\mathrm{T}+1$ mice (Fig. 7 ). As reported previously (French et al., 2001), NGFI-B in the naive hippocampus was almost exclusively expressed in area CA1. Contextual fear conditioning induced a significant threefold CA1-specific increase of NGFI-B expression in the hippocampus $1 \mathrm{~h}$ after training (counts above threshold: naive, $102 \pm 23 ; \mathrm{T}+1,334 \pm 52$; one-way $\operatorname{ANOVA} ; F_{(1,46)}=17.0$; $p<0.001)$. 
A

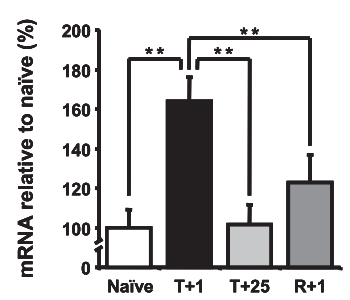

B

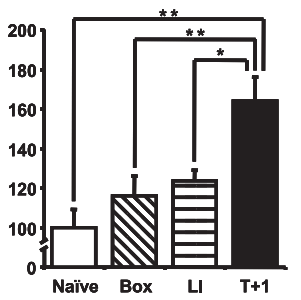

C

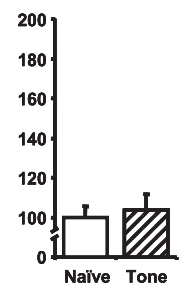

Figure 6. NGFI- $B$ mRNA expression in the hippocampus is upregulated during contextshock memory consolidation but not reconsolidation. $A$, qPCR showed that NGFI-B mRNA expression was upregulated in the hippocampus $1 \mathrm{~h}$ after contextual fear conditioning but not $1 \mathrm{~h}$ after context-shock memory reactivation. $B, N G F I-B$ mRNA expression in the hippocampus in the $T+1$ group differed significantly from expression in the Box and LI groups; the expression in both control groups did not differ significantly from that in the naive group (naïve and $T+1$ are the same as in $\boldsymbol{A}$ ). Data are means \pm SEM; ${ }^{*} p<0.05 ;{ }^{* *} p<0.01$. C, NGFI-B mRNA expression in the hippocampus did not significantly differ between the naive and Tone groups. Thus, the upregulation after contextual fear conditioning was specific for the learned association.

\section{Naive}
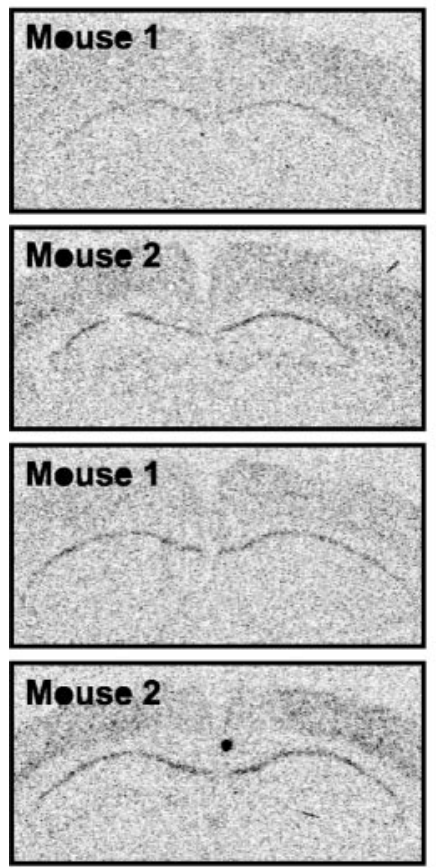
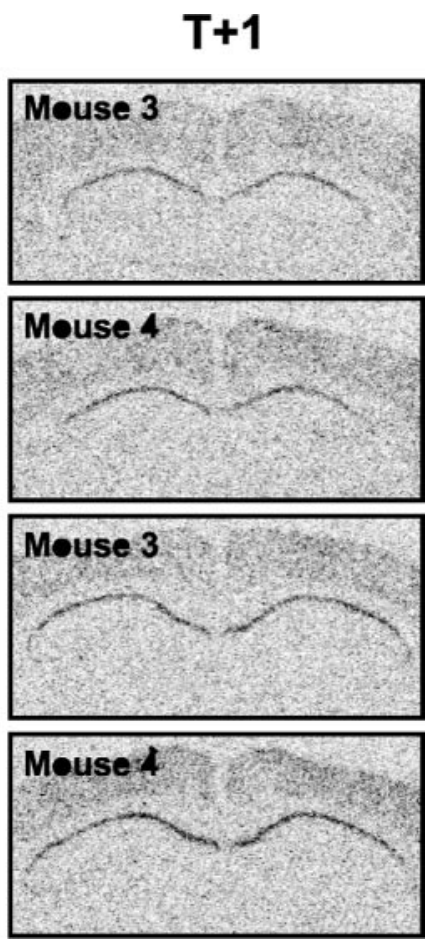

Figure 7. Upregulation of NGFI-B mRNA expression in the hippocampus during contextshock memory consolidation occurred predominantly in area CA1. Representative in situ hybridizations of coronal brain sections indicating NGFI-B expression in naive and T+1 mice $(n=2$ mice per group) are shown.

\section{Discussion}

Unspecific transcriptions induced by contextual conditioning are not suitable to study memory consolidation

SGK1 is a multifunctional serine/threonine kinase (for review, see Firestone et al., 2003). We found that hippocampal SGK1 expression was upregulated after contextual fear conditioning, a result consistent with a recent study (Levenson et al., 2004). However, our control experiments showed that the upregulation of SGK1 expression was not specific to the context-shock association, because there was no significant difference between the Box, LI, and T +1 groups. Furthermore, the upregulation in the $\mathrm{T}+1$ group was equal to the summed upregulation in the Box and LI groups (51\% for Box, $70 \%$ for $\mathrm{LI}$, and $121 \%$ for $\mathrm{T}+1$ ), indi-

cating no association-specific increment in SGK1 upregulation in the $\mathrm{T}+1$ group. Similar unspecific expression changes after contextual fear conditioning have been described for other IEGs, such as zif268 and c-fos (Hall et al., 2000; Stanciu et al., 2001).

The fact that these IEGs are not specific to the context-shock association does not necessarily mean that they are not important for hippocampal memory formation. SGK1, for example, has recently been implicated in hippocampus-dependent learning and memory (L\&M). Hippocampal SGK1 expression is induced by water maze training (Tsai et al., 2002) and environmental enrichment (Lee et al., 2003), a procedure known to improve hippocampus-dependent L\&M (Duffy et al., 2001; Need and Giese, 2003). Furthermore, SGK1 is required for spatial memory formation in the water maze (Tsai et al., 2002). Similarly, zif268 is required for consolidation of object recognition memory (Jones et al., 2001; Bozon et al., 2003).

However, the fact that these IEGs are unspecifically regulated after contextual fear conditioning means that they are not suitable molecular markers of transcriptional processes underlying memory consolidation, although such genes may be required for memory formation.

\section{SGK3 and NGFI-B are upregulated during context-shock} memory consolidation

Our studies are the first to implicate SGK3, an isoform of SGK-1, in memory formation. We found that hippocampal SGK3 expression was transiently upregulated after contextual fear conditioning, and this upregulation was specific to the context-shock association. SGK3 is therefore a suitable marker to study contextshock memory consolidation. SGK3 has been shown to activate the Shaker-related $\mathrm{K}_{\mathrm{v}} 1$ potassium channels (Warntges et al., 2002; Gamper et al., 2002a,b). It is therefore conceivable that SGK3 regulates the activity of voltage-gated potassium channels and hence neuronal excitability, a putative L\&M mechanism (Giese et al., 2001).

Our findings also implicate NGFI-B (also called nur77 or N10) in memory formation. NGFI-B belongs to the orphan nuclear receptor family of transcription factors (for review, see Maruyama et al., 1998). Hippocampal NGFI-B expression is upregulated after seizure (French et al., 2001) and downregulated by environmental enrichment (Olsson et al., 1994). Furthermore, contextual fear conditioning induces an upregulation of NGFI-B expression in the amygdala and neocortex in rats, which appears to be specific for associative learning (Malkani and Rosen, 2000). We found that NGFI-B expression was transiently upregulated after contextual fear conditioning in mice, and this upregulation was specific to the context-shock association. Using in situ hybridization, we confirmed that $N G F I-B$ was upregulated during consolidation and detected the upregulation specifically in area CA1. Our result appears to disagree with the previous finding that $N G F I-B$ expression is not altered in area CA1 of the hippocampus in the rat $1 \mathrm{~h}$ after contextual fear conditioning (Malkani and Rosen, 2000). However, in the latter study, saturation of the in situ hybridization signal is likely to have masked the transcriptional change.

\section{Evidence for the involvement of the hippocampus in} mediating context-shock associations

Contextual fear memory is thought to depend on two processes: (1) the construction of a representation of the context and (2) the formation of an association of that representation with the shock. The context representation is believed to be mediated by the hippocampus (Rudy et al., 2002), whereas there is debate as to 
where the context-shock association is generated and stored. We found that $S G K 1$ was upregulated by the context, suggesting that $S G K 1$ contributes to the hippocampal representation of the context. In contrast, NGFI-B and SGK3 were specifically regulated by the context-shock association and are therefore likely to contribute to the storage of the learned association. This molecular evidence suggests that during contextual fear memory consolidation, the hippocampus is involved in both establishing a contextual representation as well as forming a context-shock memory. In contrast to the role of the hippocampus, the amygdala seems to modulate contextual fear memory formation (Moita et al., 2003; Huff and Rudy, 2004; McGaugh, 2004).

\section{An association-specific transcription can be recapitulated during contextual memory reconsolidation}

The expression pattern of $S G K 1$ is very similar to that previously described for zif268 (Hall et al., 2000, 2001). Both genes, in addition to being regulated after conditioning and reactivation, are also regulated by the shock alone. Thus, these genes may be fear regulated, which implies that one cannot determine whether the upregulation observed after context-shock memory reactivation is attributable to fear, to memory reactivation, or both. Therefore, these genes cannot be used to study the mechanisms underlying memory reconsolidation; only genes that are specifically regulated by the conditioned stimulus-unconditioned stimulus association are suitable for the analysis of reconsolidation.

We found that the upregulation of $S G K 3$ expression was specific to the context-shock association and that it was recapitulated during reconsolidation. This is the first report showing that a process specific to context-shock association is recapitulated after memory reactivation. Because association-specific transcriptions are very likely to contribute to memory storage, our results suggest that reconsolidation gates subsequent storage of the reactivated memory and that the reduced conditioned response elicited by inhibitor treatments is not solely, if at all, attributable to retrieval deficits as suggested by recent reports (Anokhin et al., 2002; Fischer et al., 2004; Lattal and Abel, 2004).

\section{Retrieval of remote and recent memory does not trigger the same molecular events}

We found that the expression of SGK3 was upregulated in the hippocampus by context-shock memory reactivation $24 \mathrm{~h}$ after training. Interestingly, the expression of $S G K 3$ was not altered by context-shock memory reactivation $28 \mathrm{~d}$ after the initial training. A recent study has demonstrated that remote contextual memories are more stable than recent memories and require a longer reactivation session to become sensitive to disruption by anisomycin (Suzuki et al., 2004). It is therefore possible that $28 \mathrm{~d}$ after conditioning, a longer reexposure would be required to induce a context-shock memory reactivation-specific upregulation of $S G K 3$. Nonetheless, our results show that the hippocampal processes occurring during reconsolidation of contextual memory change over time.

\section{At the molecular level, memory reconsolidation does not recapitulate consolidation}

We found that the expression of SGK3 was upregulated during consolidation and reconsolidation of recent memories. This recapitulated expression showed that the hippocampus is engaged in both the consolidation and the reconsolidation of contextual fear memory, a finding consistent with previous studies (Debiec et al., 2002). Both $S G K 3$ and NGFI-B were specifically regulated by the context-shock association during consolidation; however, only SGK3 was upregulated during reconsolidation. The consolidation-specific expression of NGFI-B shows that reconsolidation is not a mere recapitulation of consolidation. Recently, $B D N F$ was shown to be required specifically for consolidation, but not reconsolidation, of contextual fear memory (Lee et al., 2004). However, the expression profile of BDNF during reconsolidation has not been reported, and thus it is not known whether the upregulation of BDNF expression is consolidation specific. Therefore, the analysis of NGFI-B expression shows for the first time that a consolidation-specific transcription exists. The finding of consolidation-specific transcription together with repeated transcriptions suggests that reconsolidation is a partial recapitulation of consolidation, engaging only a subset of processes involved in memory consolidation. Our hypothesis is not in contrast with a recent study that showed that knock-down of zif268 expression impairs reconsolidation but not consolidation of contextual fear memory (Lee et al., 2004). zif268 expression is upregulated after contextual fear conditioning and memory reactivation (Hall et al., 2000, 2001). Therefore, the study by Lee et al. (2004) suggests that there may be less functional redundancies during reconsolidation than during consolidation. Contextual fear conditioning may trigger the expression of consolidationspecific genes that are functionally redundant to zif268; such genes would not be expressed during reconsolidation, resulting in an impairment of memory reconsolidation in the absence of zif268. Such an interpretation is consistent with our finding of a consolidation-specific transcription.

\section{Conclusion}

Our findings show for the first time that expression changes specific to the context-shock association can be recapitulated during reconsolidation. This is consistent with the idea that the reconsolidation processes triggered by contextual fear memory retrieval are engaged again in subsequent storage of the reactivated context-shock memory. In addition, we show that reconsolidation processes in the hippocampus change over time, because retrieval of remote memories does not trigger the transcriptional changes induced by retrieval of recent memories. Finally, we demonstrate that memory reactivation induces only a subset of the transcriptional events occurring during consolidation. Thus, we hypothesize that memory reconsolidation is a partial recapitulation of memory consolidation. Such partial rather than total recapitulation may have evolved as a more economic and reliable mechanism for an organism to modify a memory.

\section{References}

Anokhin KV, Tiunova AA, Rose SP (2002) Reminder effects-reconsolidation or retrieval deficit? Pharmacological dissection with protein synthesis inhibitors following reminder for a passive-avoidance task in young chicks. Eur J Neurosci 15:1759-1765.

Bahar A, Dorfman N, Dudai Y (2004) Amygdalar circuits required for either consolidation or extinction of taste aversion memory are not required for reconsolidation. Eur J Neurosci 19:1115-1118.

Bozon B, Davis S, Laroche S (2003) A requirement for the immediate early gene zif268 in reconsolidation of recognition memory after retrieval. Neuron 40:695-701.

Debiec J, LeDoux JE, Nader K (2002) Cellular and systems reconsolidation in the hippocampus. Neuron 36:527-538.

Dudai Y (2004) The neurobiology of consolidations, or, how stable is the engram? Annu Rev Psychol 55:51-86.

Duffy SN, Craddock KJ, Abel T, Nguyen PV (2001) Environmental enrichment modifies the PKA-dependence of hippocampal LTP and improves hippocampus-dependent memory. Learn Mem 8:26-34.

Firestone GL, Giampaolo JR, O’Keeffe BA (2003) Stimulus-dependent regulation of serum and glucocorticoid inducible protein kinase (SGK) tran- 
scription, subcellular localization and enzymatic activity. Cell Physiol Biochem 13:1-12.

Fischer A, Sananbenesi F, Schrick C, Spiess J, Radulovic J (2004) Distinct roles of hippocampal de novo protein synthesis and actin rearrangement in extinction of contextual fear. J Neurosci 24:1962-1966.

French PJ, O'Connor V, Voss K, Stean T, Hunt SP, Bliss TVP (2001) Seizure-induced gene expression in area CA1 of the mouse hippocampus. Eur J Neurosci 14:2037-2041.

Gamper N, Fillon S, Huber SM, Feng Y, Kobayashi T, Cohen P, Lang F (2002a) IGF-1 up-regulates $\mathrm{K}^{+}$channels via $\mathrm{PI}_{3}$-kinase, PDK1 and SGK1. Pflügers Arch 443:625-634.

Gamper N, Fillon S, Feng Y, Friedrich B, Lang PA, Henke G, Huber SM, Kobayashi T, Cohen P, Lang F (2002b) $\mathrm{K}^{+}$channel activation by all three isoforms of serum- and glucocorticoid-dependent protein kinase SGK. Pflügers Arch 445:60-66.

Giese KP, Peters M, Vernon J (2001) Modulation of excitability as a learning and memory mechanism: a molecular genetic perspective. Physiol Behav 73:803-810.

Hall J, Thomas KL, Everitt BJ (2000) Rapid and selective induction of BDNF expression in the hippocampus during contextual learning. Nat Neurosci 3:533-535.

Hall J, Thomas KL, Everitt BJ (2001) Cellular imaging of zif268 expression in the hippocampus and amygdala during contextual and cued fear memory retrieval: selective activation of hippocampal CA1 neurons during the recall of contextual memories. J Neurosci 21:2186-2193.

Huff NC, Rudy JW (2004) The amygdala modulates hippocampusdependent context memory formation and stores cue-shock associations. Behav Neurosci 118:53-62.

Jones MW, Errington ML, French PJ, Fine A, Bliss TVP, Garel S, Charnay P, Bozon B, Laroche S, Davis S (2001) A requirement for the immediate early gene zif268 in the expression of late LTP and long-term memories. Nat Neurosci 4:289-296.

Kida S, Josselyn SA, de Ortiz SP, Kogan JH, Chevere I, Masushige S, Silva AJ (2002) CREB required for the stability of new and reactivated fear memories. Nat Neurosci 5:348-355.

Kim JJ, Fanselow MS (1992) Modality-specific retrograde amnesia of fear. Science 256:675-677.

Kobayashi T, Deak M, Morrice N, Cohen P (1999) Characterization of the structure and regulation of two novel isoforms of serum- and glucocorticoid-induced kinase. Biochem J 344:189-199.

Lattal KM, Abel T (2004) Behavioral impairments caused by injections of the protein synthesis inhibitor anisomycin after contextual retrieval reverse with time. Proc Natl Acad Sci USA 13:4667-4672.

Lee EH, Hsu WL, Ma YL, Lee PJ, Chao CC (2003) Enrichment enhances the expression of sgk, a glucocorticoid-induced gene, and facilitates spatial learning through glutamate AMPA receptor mediation. Eur J Neurosci 18:2842-2852.

Lee JL, Everitt BJ, Thomas KL (2004) Independent cellular processes for hippocampal memory consolidation and reconsolidation. Science 304:839-843.

Levenson JM, Choi S, Lee SY, Cao YA, Ahn HJ, Worley KC, Pizzi M, Liou HC, Sweatt JD (2004) A bioinformatics analysis of memory consolidation reveals involvement of the transcription factor c-rel. J Neurosci 24:3933-3943.

Malkani S, Rosen JB (2000) Induction of NGFI-B mRNA following contextual fear conditioning and its blockade by diazepam. Mol Brain Res 80:153-165.

Maruyama K, Tsukada T, Ohkura N, Bandoh S, Hosono T, Yamaguchi K
(1998) The NGFI-B subfamily of the nuclear receptor superfamily (review). Int J Oncol 12:1237-1243.

McGaugh JL (2004) The amygdala modulates the consolidation of memories of emotionally arousing experiences. Annu Rev Neurosci 27:1-28.

Milbrandt J (1988) Nerve growth factor induces a gene homologous to the glucocorticoid receptor gene. Neuron 1:183-188.

Milekic MH, Alberini CM (2002) Temporally graded requirement for protein synthesis following memory reactivation. Neuron 36:521-525.

Moita MA, Rosis S, Zhou Y, LeDoux JE, Blair HT (2003) Hippocampal place cells acquire location-specific responses to the conditioned stimulus during auditory fear conditioning. Neuron 37:485-497.

Nader K, Schafe GE, LeDoux JE (2000) Fear memories require protein synthesis in the amygdala for reconsolidation after retrieval. Nature 406:722-726.

Need AC, Giese KP (2003) Handling and environmental enrichment do not rescue learning and memory impairments in $\alpha \mathrm{CaMKII}^{\mathrm{T} 286 \mathrm{~A}}$ mutant mice. Genes Brain Behav 2:132-139.

Olsson T, Mohammed AH, Donaldson LF, Henriksson BG, Seckl JR (1994) Glucocorticoid receptor and NGFI-A gene expression are induced in the hippocampus after environmental enrichment in adult rats. Mol Brain Res 2:349-353.

Phillips RG, LeDoux JE (1994) Lesions of the dorsal hippocampal formation interfere with background but not foreground contextual fear conditioning. Learn Mem 1:34-44.

Rudy JW, Barrientos RM, O'Reilly RC (2002) Hippocampal formation supports conditioning to memory of a context. Behav Neurosci 116:530-538

Sara SJ (2000) Retrieval and reconsolidation: toward a neurobiology of remembering. Learn Mem 7:73-84.

Silva AJ, Giese KP (1994) Plastic genes are in! Curr Opin Neurobiol 4:413-420.

Stanciu M, Radulovic J, Spiess J (2001) Phosphorylated cAMP response element binding protein in the mouse brain after fear conditioning: relationship to Fos production. Mol Brain Res 94:15-24.

Strekalova T, Zorner B, Zacher C, Sadovska G, Herdegen T, Gass P (2003) Memory retrieval after contextual fear conditioning induces c-Fos and JunB expression in CA1 hippocampus. Genes Brain Behav 2:3-10.

Suzuki A, Josselyn SA, Frankland PW, Masushige S, Silva AJ, Kida S (2004) Memory reconsolidation and extinction have distinct temporal and biochemical signatures. J Neurosci 24:4787-4795.

Taubenfeld SM, Milekic MH, Monti B, Alberini CM (2001) The consolidation of new but not reactivated memory requires hippocampal C/EBP $\beta$. Nat Neurosci 4:813-818.

Tronel S, Sara SJ (2002) Mapping of olfactory memory circuits: regionspecific c-fos activation after odor-reward associative learning or after its retrieval. Learn Mem 9:105-111.

Tsai KJ, Chen SK, Ma YL, Hsu WL, Lee EH (2002) Sgk, a primary glucocorticoid induced gene, facilitates memory consolidation of spatial learning in rats. Proc Natl Acad Sci USA 99:3990-3995.

Warntges S, Friedrich B, Henke G, Duranton C, Lang PA, Waldegger S, Meyermann R, Kuhl D, Speckmann EJ, Obermuller N, Witzgall R, Mack AF, Wagner HJ, Wagner A, Broer S, Lang F (2002) Cerebral localization and regulation of the cell volume-sensitive serum- and glucocorticoiddependent kinase SGK1. Pflügers Arch 443:617-624.

Webster MK, Goya L, Ge Y, Maiyar AC, Firestone GL (1993) Characterization of sgk, a novel member of the serine/threonine protein kinase gene family which is transcriptionally induced by glucocorticoids and serum. Mol Cell Biol 13:2031-2040. 